\title{
Nickel-Iron Layered Double Hydroxide for Highly Efficient Oxygen Evolution Reaction
}

\author{
Qiuyu Zhao ${ }^{1}$ Wenke $\mathrm{Xi}^{1}$ and Jianjun Wang ${ }^{1 *}$ \\ ${ }^{1}$ MOE Key Laboratory of Resources and Environmental Systems Optimization, College of Environmental Science and Engineering, North \\ China Electric Power University, Beijing 102206, PR China
}

\begin{abstract}
It is extensively accepted that electrolysis of water producing regenerable energy is a crucial substitution of traditional fuel strategy. Herein, we report a wet-chemical route to $\mathrm{Ni}$-Fe layered double hydroxide (LDH) interconnected nanosheets with large surface area with the support of vertically aligned $\mathrm{ZnO}$ microrods arrays on the nickel foam (Ni-Fe LDH@ZnO/NF) for oxygen evolution reaction. Owing to the 2D Ni-Fe LDH nanosheets distributed in 3D space, the Ni-Fe LDH@ZnO/NF demonstrates excellent OER performances with a reasonably low overpotential of $271 \mathrm{mV}$ at a current density of $10 \mathrm{~mA} \cdot \mathrm{cm}^{-2}$, and a long-term stability up to 29 hours. This work proposes a new strategy to prepare Ni-Fe LDH/NF as efficient OER catalyst.
\end{abstract}

\section{Introduction}

With the development of industry and increase of population, it is of great urgency to product clean regenerable energy to replace fossil fuels. Hydrogen is considered as one of the most promising candidates because of its environmental friendliness and recyclability $[1,2]$. Among the various methods of hydrogen production, electrolysis of water can be coupled with the wind energy or photovoltaic system which has been considered as the main way of hydrogen production in the future [3]. However, the important half-reactions in the water electrolysis process-oxygen evolution reaction (OER) - involving a four-electron reaction is constrained a sluggish kinetics, which generally requires a high overpotential to drive the reaction $[4,5]$. Currently, $\mathrm{RuO}_{2}$ and $\mathrm{IrO}_{2}$ have been demonstrated to be effective electrocatalysts for OER [6,7], but high cost and resource scarcity hinder their practical applications [8, 9]. Consequently, it is of elementary significance to engineer competent, low-cost and stable OER catalysts [10, 11$]$.

Up to now, the improvement of the performance of electrocatalytic catalysts contains three main approaches: (1) increasing the catalytic specific surface area of material to expose more catalytic active sites; (2) enhancing the stability through material structure design; (3) improving the catalyst's electrical conductivity by integrating other components [12]. However, the mentioned enhancement strategies towards electrocatalytic materials still require numerous efforts to decrease the produced and maintained cost, prevent the secondary pollution, and promote the practical applications.

Among of Ni-Fe-based catalysts [13-17], particularly $\mathrm{Ni}-\mathrm{Fe}$ layered double hydroxides (LDHs) have been extensively investigated, with a significant improvement of OER activity by structural design [18-22]. For example, Lou's group synthesized Ni-Fe LDH double-shelled nanocages exhibited an overpotential of $246 \mathrm{mV}$ in $1.0 \mathrm{M}$ $\mathrm{KOH}$, which is lower than $261 \mathrm{mV}$ by conventional $\mathrm{Ni}-\mathrm{Fe}$ LDH single-shelled nanocages at $20 \mathrm{~mA} \cdot \mathrm{cm}^{-2}$ [18]. Shi et al. reported the immobilization of Ni-Fe LDH nanoplates reduced graphene oxide. Interestingly, the $\mathrm{Ni}-\mathrm{Fe}$ LDH/3D-ErGO showed a higher OER activity with an overpotential of $259 \mathrm{mV}$ than that of Ni-Fe LDH/2DErGO $(278 \mathrm{mV})$ at $10 \mathrm{~mA} \cdot \mathrm{cm}^{-2}$ because of the large electrochemically active surface area of Ni-Fe/3D-ErGO [19]. However, improvement of poor stability and low conductivity of Ni-Fe LDH $[20,21]$ is still challenging towards its practical application.

Herein, we reported a wet-chemical route to synthesis $\mathrm{Ni}-\mathrm{Fe}$ LDH@ZnO on nickel foam (denoted as Ni-Fe $\mathrm{LDH} @ \mathrm{ZnO} / \mathrm{NF}$ ), and then we investigated their electrochemical properties via serial characterizations and experiments. The result illustrated that $\mathrm{Ni}-\mathrm{Fe}$ LDH@ZnO/NF exhibited excellent oxygen evolution reaction (OER) activity and long-term stability, which was ascribed to the effective enhancement catalytic surface area after the introduction of $\mathrm{Ni}-\mathrm{Fe} \mathrm{LDH}$ onto $\mathrm{ZnO}$ microrods arrays.

\section{Experimental section}

Growth of $\mathrm{ZnO}$ microrods arrays on nickel foam ( $\mathrm{ZnO} / \mathrm{NF})$ : Commercial nickel foam (NF) was ultrasonically washed with concentrated $\mathrm{HCl}(\sim 37 \mathrm{wt} \%)$, ethanol and ultrapure water for $10 \mathrm{~min}$, successively. Treated NF was then dropped into Teflon-lined stainless reactors $(50 \mathrm{~mL})$ containing $40 \mathrm{~mL}$ ultrapure water, 0.030 $\mathrm{M} \mathrm{Zn}\left(\mathrm{NO}_{3}\right)_{2} \cdot 6 \mathrm{H}_{2} \mathrm{O}$, and $0.025 \mathrm{M} \mathrm{C}_{6} \mathrm{H}_{12} \mathrm{~N}_{4}$. After the

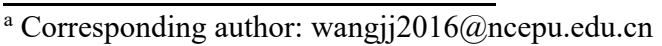


hydrothermal reaction conducting at $100{ }^{\circ} \mathrm{C}$ for $6 \mathrm{~h}$, the uniform $\mathrm{ZnO}$ microrods were generated on NF.

Synthesis of Ni-Fe LDH@ZnO/NF: $\mathrm{NiFeS}_{\mathrm{x}}$ was grown on the surface of $\mathrm{ZnO}$ microrods by electrochemical cathode deposition at $70{ }^{\circ} \mathrm{C}$ in the 0.010 $\mathrm{M} \mathrm{NiCl}_{2}$ and $0.001 \mathrm{M} \mathrm{FeCl}_{3}+0.100 \mathrm{M} \mathrm{Na}_{2} \mathrm{~S}_{2} \mathrm{O}_{3}(10 \mathrm{~mL})$ aqueous solution at $1.0 \mathrm{~mA} \cdot \mathrm{cm}^{-2}$ for 600 seconds. After drying, the $\mathrm{NiFeS}_{\mathrm{x}}$ was soaked in a 2-methylimidazole aqueous solution $(0.10 \mathrm{M}, 20 \mathrm{~mL})$ at $90{ }^{\circ} \mathrm{C}$ for $2 \mathrm{~h}$ to obtain Ni-Fe LDH@ZnO/NF. For comparison, Ni-Fe LDH on NF (Ni-Fe LDH/NF) was synthesized by using the same method without $\mathrm{ZnO}$ microrods arrays.

\section{Results and discussion}

The Ni-Fe LDH@ZnO/NF mesostructured microrods were synthesized via wet-chemical route. Firstly, Hexagonal prism $\mathrm{ZnO}$ microrods arrays with an average lateral length of $1.2 \mu \mathrm{m}$ were in-situ grown on NF ( $\mathrm{ZnO} / \mathrm{NF}$ ) by hydrothermal method. Secondly, a NiFeSx layer was electrodeposited on the surface of $\mathrm{ZnO} / \mathrm{NF}$ (Figure. 1(a, b)). Finally, Ni-Fe LDH grew on the outside of $\mathrm{ZnO}$ via the reduction of $\mathrm{NiFeSx}$ by using 2methylimidazole (Figure. 1(c, d)). As we can see, Ni-Fe LDH was uniformly distributed with a thickness of $2 \mathrm{~nm}$ with a distinct boundary between $\mathrm{ZnO}$ microrods arrays.

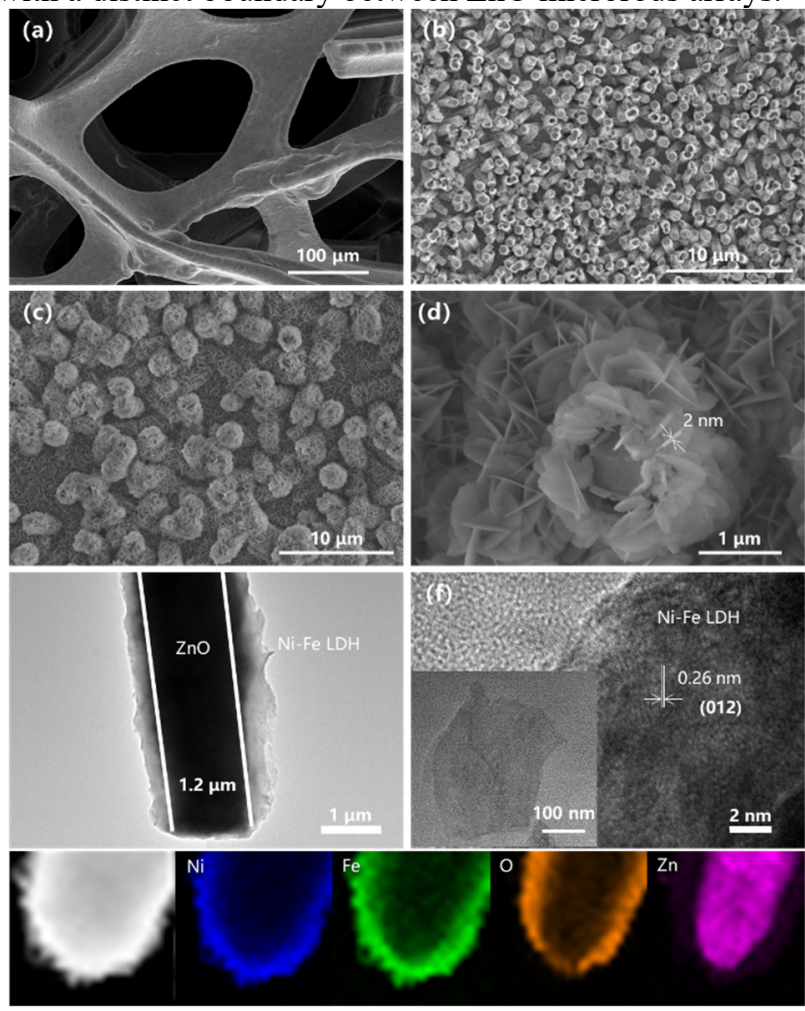

Figure 1. SEM images of NF (a) NiFeSx@ZnO/NF (b) and NiFe LDH@ZnO/NF (c and d). TEM images of Ni-Fe LDH@ZnO (e) and HRTEM (f) images of Ni-Fe LDH. Element distribution of Ni-Fe LDH@ZnO (g).

TEM images of Ni-Fe LDH@ZnO and Ni-Fe LDH were shown as Figure. 1(e, f). The layered structure of NiFe LDH was well maintained after decorated on the surface of $\mathrm{ZnO}$ microrods arrays. High-resolution image of TEM (HRTEM) revealed a lattice fringe distance of $0.26 \mathrm{~nm}$, which corresponded to the spacing of $(012)$ lattice plane of Ni-Fe LDH [22]. The image of TEM element mapping (Figure. 1(g)) indicated a homogeneous elemental distribution of $\mathrm{Ni}, \mathrm{Fe}, \mathrm{Zn}$, and $\mathrm{O}$, which further verified that the successful synthetization of $\mathrm{Ni}-\mathrm{Fe}$ $\mathrm{LDH} / \mathrm{ZnO}$.

The X-ray diffraction (XRD) patterns of Ni-Fe LDH@ZnO/NF, Ni-Fe LDH/NF, ZnO/NF, and NF were displayed in Figure. 2(a). The peaks at $2 \theta=13.1^{\circ}, 19.5^{\circ}$ and $33.7^{\circ}$ can be attributed to (003), (006) and (009) planes of Ni-Fe LDH nanosheets (Figure. 2(b)) [23], indicating that $\mathrm{LDH}$ was successfully loaded on the $\mathrm{ZnO}$ $\left(2 \theta=32^{\circ}, 34.6^{\circ}\right.$ and $\left.36.4^{\circ}\right)$ [24]. To investigate the electrocatalytic OER active sites, quasi real-time Raman spectra were obtained at different potential as shown in Figure. 2(c). The Raman bands at $484 \mathrm{~cm}^{-1}$ and $564 \mathrm{~cm}^{-1}$ correspond to $\gamma-\mathrm{NiOOH}\left(\mathrm{Ni}^{3+}\right)$ [25]. The band intensities were changed with the increase of potential, indicating that the content of oxyhydroxides increased at the high potential. This revealed that oxyhydroxide was the active catalytic substance of OER. Thus, in line with the previous reports $[23,30]$, the oxyhydroxide was active for OER in our study. Besides, the peak at $1060 \mathrm{~cm}^{-1}$ was assigned to intercalated carbonate in Ni-Fe LDH.
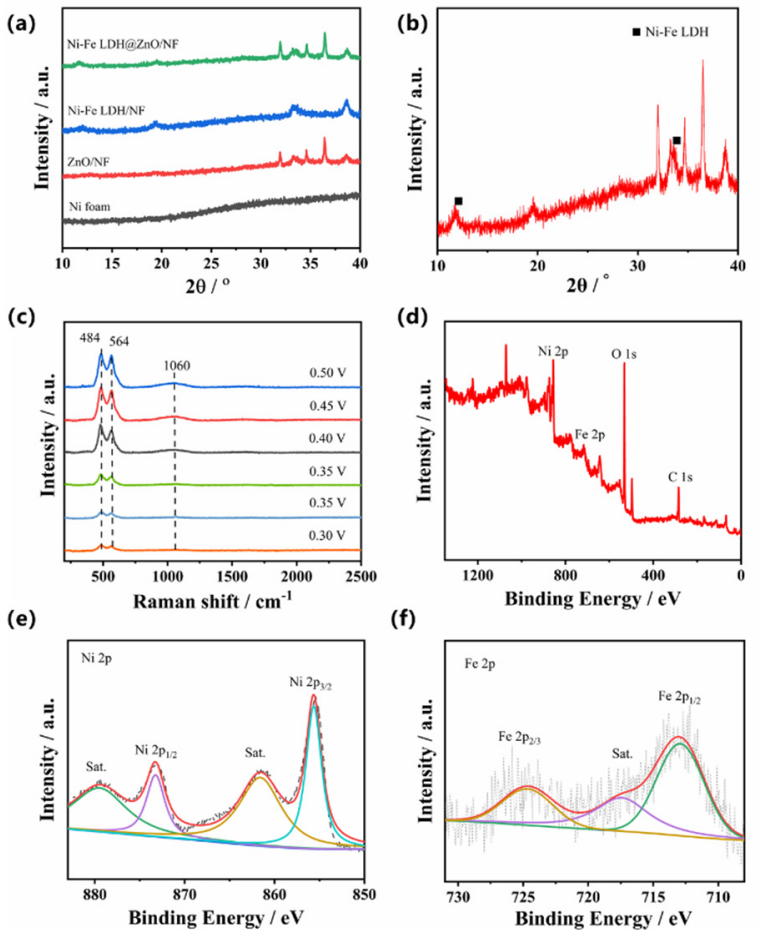

Figure 2. (a) and (b) XRD patterns of $\mathrm{Ni}$ foam, $\mathrm{ZnO} / \mathrm{NF}, \mathrm{Ni}-\mathrm{Fe}$ LDH/NF, and Ni-Fe LDH@ZnO/NF. (c) In-situ Raman spectra of Ni-Fe LDH@ZnO/NF recorded at varied potentials during OER process. (d) XPS survey spectrum of Ni-Fe LDH@ZnO/NF. (e) and (f) High-resolution Ni 2p spectrum and Fe 2p of Ni-Fe LDH@ZnO/NF, respectively.

The X-ray photoelectron spectroscopy (XPS) spectra recorded on the surface of Ni-Fe LDH@ZnO/NF revealed the presence of Ni 2p, Fe 2p, and O 1s (Figure. 2(d)). The high-resolution XPS spectrum of Ni $2 p$ in Figure. 2(e) showed a binding energy difference between two spinorbit peaks, which was related to $\mathrm{Ni}-\mathrm{O}\left(\mathrm{Ni} 2 \mathrm{p}_{1 / 2}\right.$ at 873.43 $\mathrm{eV})$ and $\mathrm{Ni}-\mathrm{OH}\left(\mathrm{Ni} 2 \mathrm{p}_{3 / 2}\right.$ at $855.73 \mathrm{eV}$ ) [26]. Figure. 2(f) showed the divided $\mathrm{Fe} 2 \mathrm{p}_{3 / 2}$ and $\mathrm{Fe} 2 \mathrm{p}_{1 / 2}$ were affiliated with iron oxides or hydroxides such as $\mathrm{Fe}_{2} \mathrm{O}_{3}, \mathrm{Fe}_{3} \mathrm{O}_{4}$, and 
$\mathrm{FeOOH}$. Though oxygen evolution reaction mechanisms demonstrated that the active variety was $\mathrm{Ni}^{2+}$ in the vicinity of $\mathrm{Fe}$ ions. With the $\mathrm{Fe}$ incorporation, overpotential of OER was significantly reduced, which was attributed to $\mathrm{Ni}^{3+}$ reduced to $\mathrm{Ni}^{2+}$ by $\mathrm{H}$ transfer around $\mathrm{Fe}^{2+}$. Both Ni $2 \mathrm{p}$ and $\mathrm{Fe} 2 \mathrm{p}$ exhibited same ingredient of $\mathrm{Ni}-\mathrm{Fe} \mathrm{LDH}$, verifying the existence of LDH. Zn $2 p$ was not detected by XPS and we believe that it is due to the dense coverage of Ni-Fe LDH nanosheets $(\sim 200 \mathrm{~nm})$ on the surface of $\mathrm{ZnO}$ which can be seen from the TEM image.

(a)

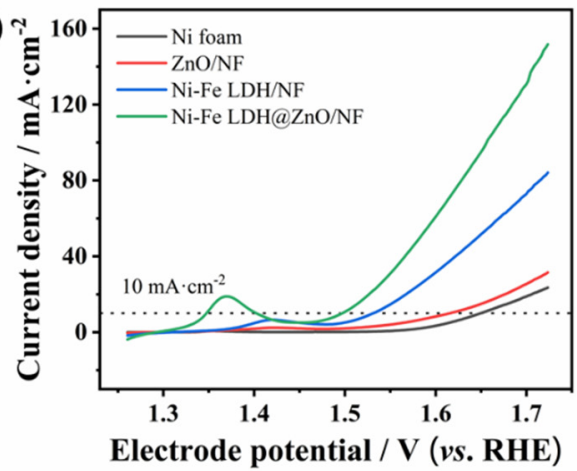

(b)

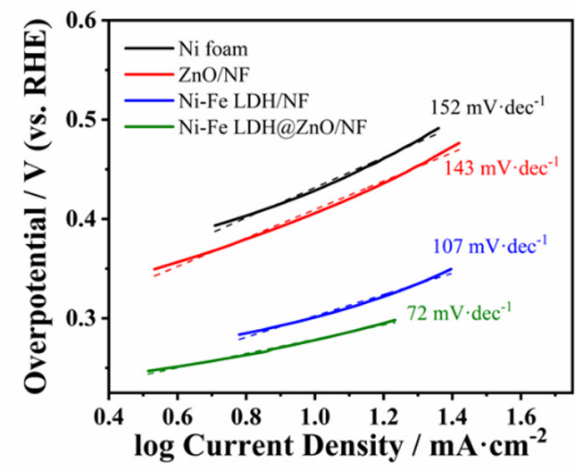

(c)

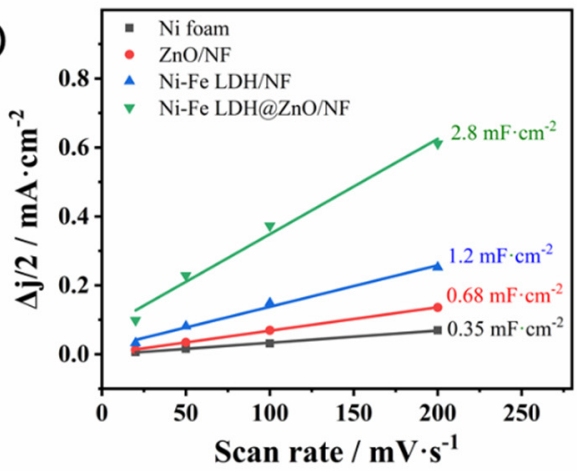

(d)

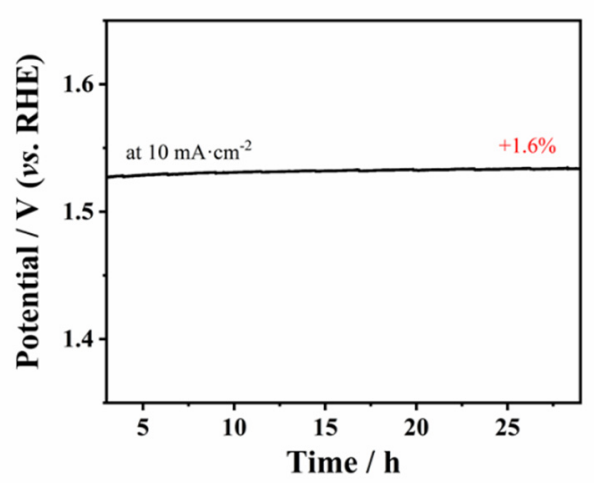

Figure 3. (a)-(c) LSV curves, Tafel plots and Double-layer capacitance (Cdl) plots of NF, ZnO/NF, Ni-Fe LDH/NF, and Ni-Fe LDH@ZnO/NF. (d) Stability measurement of Ni-Fe LDH@ZnO/NF at the current density of $10 \mathrm{~mA} \cdot \mathrm{cm}^{-2}$.

The OER performances of Ni-Fe LDH@ZnO/NF was evaluated in $1.0 \mathrm{M} \mathrm{KOH}$ at the ambient condition. Figure. 3(a) showed its linear sweep voltammetry (LSV) curves. Ni-Fe LDH@ZnO/NF exhibited the lowest overpotential of $271 \mathrm{mV}$ at $10 \mathrm{~mA} \cdot \mathrm{cm}^{-2}$ (NF $419 \mathrm{mV}, \mathrm{ZnO} / \mathrm{NF} 386 \mathrm{mV}$ and $\mathrm{Ni}-\mathrm{Fe} \mathrm{LDH} / \mathrm{NF} 303 \mathrm{mV}$ ). It was worth noting that, the overpotential of Ni-Fe LDH@ZnO/NF was reduced by 32 $\mathrm{mV}$ in comparison with $\mathrm{Ni}-\mathrm{Fe} \mathrm{LDH} / \mathrm{NF}$ which resulted from the introduction of $\mathrm{ZnO}$. The Tafel slope of $\mathrm{Ni}-\mathrm{Fe}$ $\mathrm{LDH} @ \mathrm{ZnO} / \mathrm{NF}$ was calculated to be $72 \mathrm{mV} \cdot \mathrm{dec}^{-1}$ (Figure. 3(b)), which was lower than that of Ni-Fe LDH/NF (107 $\left.\mathrm{mV} \cdot \mathrm{dec}^{-1}\right), \mathrm{ZnO} / \mathrm{NF}\left(143 \mathrm{mV} \cdot \mathrm{dec}^{-1}\right)$, and $\mathrm{NF}(152$ $\left.\mathrm{mV} \cdot \mathrm{dec}^{-1}\right)$. This indicated that Ni-Fe LDH@ZnO/NF possessed a faster kinetics towards OER due to the increase of $\gamma-\mathrm{NiOOH}$ and 3D structure. The ECSA was studied through the double-layer capacitance $(\mathrm{Cdl})$ (Figure. 3(c) and Figure. 4(a-d)). ECSA with values of 2.8 $\mu \mathrm{F} \cdot \mathrm{cm}^{-2}, 1.2 \mu \mathrm{F} \cdot \mathrm{cm}^{-2}, 0.68 \mu \mathrm{F} \cdot \mathrm{cm}^{-2}, 0.35 \mu \mathrm{F} \cdot \mathrm{cm}^{-2}$ were obtained for Ni-Fe LDH@ZnO/NF, Ni-Fe LDH/NF, $\mathrm{ZnO} / \mathrm{NF}$ and NF, respectively. Ni-Fe LDH@ZnO (3D) had a larger ECSA than Ni-Fe LDH (2D) with the existence of $\mathrm{ZnO}$. The best OER performance of Ni-Fe LDH@ZnO/NF results from the largest surface area of the materials. We also evaluated the stability of $\mathrm{Ni}-\mathrm{Fe}$ $\mathrm{LDH} @ \mathrm{ZnO} / \mathrm{NF}$ at $10 \mathrm{~mA} \cdot \mathrm{cm}^{-2}$ and it exhibited a longterm stability up to $29 \mathrm{~h}$ (with a potential increase of $1.6 \%$ ) (Figure. 3(d)).
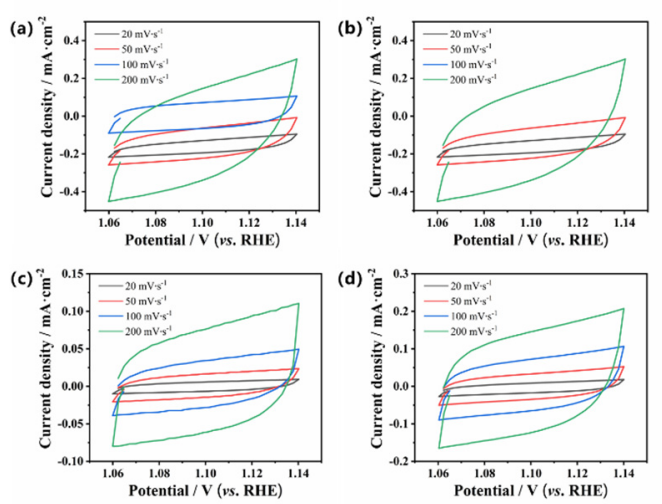

Figure 4. (a)-(d) CV curves of $\mathrm{NF}, \mathrm{ZnO} / \mathrm{NF}$, Ni-Fe LDH/NF, and Ni-Fe LDH@ZnO/NF recorded at scan rates of 20 to 200 $\mathrm{mV} \cdot \mathrm{s}^{-1}$. 


\section{Conclusion}

A novel wet-chemical method has been successfully developed for $\mathrm{Ni}-\mathrm{Fe} \mathrm{LDH}$ nanosheets on $\mathrm{ZnO}$ microrods. Multiple characteristic technologies such as SEM, TEM, $\mathrm{XRD}$, and XPS were conducted to conformed the accessibility of this method. The Ni-Fe LDH@ZnO/NF exhibited excellent OER catalytic ability with an overpotential of $271 \mathrm{mV}$ at $10 \mathrm{~mA} \cdot \mathrm{cm}^{-2}$ as well as longterm stability up to $29 \mathrm{~h}$ with potential increase of $1.6 \%$. The excellent OER activities of LDH@ZnO/NF were owing to a larger catalytic surface area and more catalytically active sites.

\section{Acknowledgments}

The work was financially supported by National Natural Science Foundation of China (11875028).

\section{References}

1. R. Zhang, X. Wang, S. Yu, T. Wen, X. Zhu, F. Yang, X. Sun, X. Wang, W. Hu, Adv. Mater 29, 1605502 (2017)

2. M. S. Dresselhaus, I. L. Thomas, Nature 414, 332 (2001)

3. I. Roger, M. A. Shipman, M. D. Symes, Nat. Rev. Chem 1, 0003 (2017)

4. C. C. L. McCrory, S. Jung, J. C. Peters, T. F. Jaramillo, J. Am. Chem. Soc 135, 16977 (2013)

5. M. G. Walter, E. L. Warren, J. R. McKone, S. W. Boettcher, Q. Mi, E. A. Santori, N. S. Lewis, Chem. Rev 110, 6446 (2010)

6. J. Kibsgaard, I. Chorkendorff, Nat. Energy 4, 430 (2019)

7. J. W. D. Ng, M. Garcia-Melchor, M. Bajdich, P. Chakthranont, C. Kirk, A. Vojvodic, T. F. Jaramillo, Nat. Energy 1, 16053 (2016)

8. E. A. Paoli, F. Masini, R. Frydendal, D. Deiana, C. Schlaup, M. Malizia, T. W. Hansen, S. Horch, I. E. L. Stephens, I. Chorkendorff. Chem. Sci 6, 190 (2015)

9. D. Y. Kuo, J. K. Kawasaki, J. N. Nelson, J. Kloppenburg, G. Hautier, K. M. Shen, D. G. Schlom, J. Suntivich, J. Am. Chem. Soc 139, 3473 (2017)

10. F M. S. Faber, S. Jin, Energ. Environ. Sci 7, 3519 (2014)

11. X. Zou, Y. Zhang, Chem. Soc. Rev 44, 5148 (2015)

12. J. Zhu, L. Hu, P. Zhao, L. Y. S. Lee, K. Wong, Chem. Rev 120, 851 (2020)

13. F. Dionigi, P. Strasser, Adv. Energy Mater 6, 1600621 (2016)

14. Y. Li, G. Zhang, W. Lu, F. Cao, Adv. Sci 7, 1902034 (2020)

15. Z. Liu, C. Dong, Y. Huang, J. Cen, H. Yang, X. Chen, X. Tong, D. Su, Y. Wang, S. Wang, J. Mater. Chem. A 7, 14483 (2019)

16. C. Huang, J. Nie, Z. Xu, X. Zhang, J. Tang, B. Wang,
J. Huang, C. Du, J. Chen, Int. J. Hydrog. Energy 46, 12992 (2021)

17. X. Feng, Y. Shi, J. Shi, L. Hao, Z. Hu, Int. J. Hydrog. Energy 46, 5169. (2021)

18. J. Zhang, L. Yu, Y. Chen, X. F. Lu, S. Gao, X. Lou, Adv. Mater 32, 1906432 (2020)

19. X. Yu, M. Zhang, W. Yuan, G. Shi, J. Mater. Chem. A 3, 6921 (2015)

20. L. Wu, L. Yu, F. Zhang, D. Wang, D. Luo, S. Song, C. Yuan, A. Karim, S. Chen, Z. Ren, J. Mater. Chem. A 8, 8096 (2020)

21. N. Todoroki, T. Wadayama, Acs. Appl. Mater. Inter 11, 44161 (2019)

22. G. Zhang, J. Yuan, Y. Liu, W. Lu, N. Fu, W. Li, H. Huang, J. Mater. Chem. A 6, 10253 (2018)

23. Trotochaud, L.; Young, S. L.; Ranney, J. K.; Boettcher, S. W. J. Am. Chem. Soc 136, 6744 (2014)

24. L. Han, S. Dong, E. Wang, Adv. Mater 28, 9266 (2016)

25. J. Feng, J.Wu, Y. Tong, G. Li, J. Am. Chem. Soc 140, 610 (2018)

26. Y. Han, Z. Liu, Z. Yang, Z. Wang, X. Tang, T. Wang, L. Fan, K. Ooi, Chem. Mater 20, 360 (2008)

27. X. Wang, S. Zhou, W. Xing, B. Yu, X. Feng, L. Song, Y. Hu, J. Mater. Chem. A 1, 4383 (2013)

28. X. Fan, M. Zhang, I. Shafiq, W. Zhang, C. Lee, S. Lee, Adv. Mater 21, 2393 (2009)

29. Y. Luo, Y. Wu, D. Wu, C. Huang, D. Xiao, H. Chen, S. Zheng, P. Chu, ACS. Appl. Mater. Interfaces 12, 42850 (2020)

30. S. Klaus, Y. Cai, M. Louie, L. Trotochaud, A. Bell, J. Phys. Chem. C 119, 7243 (2015) 